\title{
Current Studies of Food and Foodways
}

\author{
Books Briefly Noted by Danille Elise Christensen
}

Culinary Capital. Peter Naccarato and Kathleen LeBesco. New York: Berg. 2012. 145 pp.

Culinary Capital draws on the work of sociologists, anthropologists, folklorists, and other scholars of vernacular performance to examine how practices with food confer social distinction. The authors watch television, read marketing materials, monitor online discussions, and conduct interviews in the field as they investigate a range of contemporary cultural institutions, from meal assembly kitchens to competitive eating contests. As they consider which social performances might be hegemonic and which resistant, Peter Naccarato and Kathleen LeBesco ponder whether new aids for home cooks (e.g., online grocers) liberate or merely shift the burden of invisible labor; in other chapters they suggest that the varied models of self and citizenship promoted on cable food shows ultimately aim to maximize consumption, and they question whether online restaurant review sites are as egalitarian as they purport to be. In the end, the authors posit that some social spaces hybridize "elitist" regimes (i.e., those that advocate local, organic, artisanal, adventurous, "information-dense" food that tells the right stories [9]) by incorporating "an increased focus on and celebration of pleasure and overindulgence" (119)these last being characteristics the authors associate with "low" carnivalesque or transgressive spaces like state fairs and junk food websites. The book will interest those concerned with the social meanings of food and the ways people work to fashion, transcend, and reinscribe value hierarchies in popular contexts. Notes $3 \mathrm{pp}$. Bibliography, 9 pp. Index, 9 pp.

\section{Global Food Futures: Feeding the World in 2050. Brian Gardner. London: Bloomsbury, 2013. 242 pp.}

In Global Food Futures, Brian Gardner evaluates the sustainability of current global food production systems and argues that catastrophic food shortages can be averted in the next half century if food production is ramped up, especially in sub-Saharan Africa and south Asia. Gardner considers the challenges of increasing food production given a range of factors, including changes in climate patterns, global demographics, diet preferences, and global economic stability, as well as the constraints imposed by fossil-fuel reliance, political instability, availability of arable land, and local infrastructures. He argues for increased economic and political investment in research that generates new resource-efficient crop varieties, addresses the consequences of global warming, and considers shifting trade patterns, and he asserts that emergent and established global players must share the burden of developing, producing, and distributing adequate and sustainable food supplies. Combining summaries of existing issues and patterns with recommendations for future action, Global Food Futures offers an accessible introduction to concepts such as food pricing, factors that shift supply and demand, definitions of sustainability, and even the difference between "food security" and "food self-sufficiency." Each

\footnotetext{
* This editorially reviewed contribution was accepted for publication in Museum Anthropology Review on June 1, 2014. The work is licensed under the Creative Commons Attribution 4.0 International License. To view a copy of this license, visit http://creativecommons.org/licenses/by/4.0/.
} 
chapter includes an introduction, summary of main points, descriptive subheads, and conclusion. Seventeen illustrations and eleven tables further emphasize important points in Gardner's discussion. Bibliography, 6 pp. Index, 8 pp.

\section{Food Words: Essays in Culinary Culture. Peter Jackson, ed. New York: Bloomsbury, 2013. 293 pp.}

Food Words brings together 61 essays that explore debates central to the study of food's place in contemporary social life. Consciously modeled on Raymond Williams's Keywords, the volume focuses on concepts-in-context as it traces the changing meanings of words from advertising to work. The twelve contributors - most of whom are based in the UK and Sweden - attend to the symbolic, material, and performed dimensions of food in both commercial and domestic spaces. Some of the terms selected for inclusion are obviously related to food studies-including appetite, celebrity chefs, consumption, foodscapes, taste-while others (authenticity, convenience, memory, pleasure, waste) have broader play. Written for an intellectually curious but general audience, the essays provide accessible introductions to categories of social difference (e.g., gender), specialized terminology (e.g., moral economy), and the often taken-forgranted (e.g., time, eating, science, trust). Essays titled "Brands," "Kitchens," "Packaging," and "Practices" are grounded in tangible referents, but the volume also includes ruminations on buzzwords such as fresh, artisan, gourmet, quality, and exotic. As would be expected from a scholarly collective known as the CONANX (Consumer Culture in an Age of Anxiety) group, the volume also addresses a range of concerns that cluster around the words choice, emotion, governance, labeling, local-global, risk, responsibility, safety, and security. Essays range in length from about 1000 words to more than 5000. American Studies scholar Warren J. Belasco offers an overview of the state of food studies in his foreword, and readers are treated to an extensive bibliography, as well as recommendations for further reading, at the close of the volume. Further Reading, 2 pp. References, 37 pp. Index, 5 pp.

\section{From Modern Production to Imagined Primitive: The Social World of Coffee from Papua New Guinea. Paige West. Durham, NC: Duke University Press, 2012. 315 pp.}

In From Modern Production to Imagined Primitive, Columbia University anthropologist Paige West offers an ethnographic exploration of how value is created as coffee from Papua New Guinea (PNG) moves through global commodity circuits. West attends to the labor involved in producing, processing, distributing, advertising, and consuming coffee from the PNG Highlands. Her fieldwork encompasses village, regional, national, and international contexts, examining the history of coffee cultivation in Papua New Guinea and its impacts on environments, identities, material conditions, and social relations. West documents on-the-ground interactions among farmers, buyers, and distributors, detailing how many of her consultants view themselves as modern actors on a global stage; in addition, she gives glimpses into the lives of marketers and the thoughts of consumers in coffee shops in London, Hamburg, Sydney, and the like. As West documents this complicated web of people, practices, and signs, she gives special emphasis to the work involved in crafting narratives that sell PNG coffee, arguing that neoliberal techniques 
for marketing specialty coffee as "single-origin" or "fair trade" hinge on fantasies that link poverty to "primitive" culture. These stories, she says, misrepresent the actual circumstances of the coffee's production and offer simplistic, fashionable solutions to the problems of alienated labor and uneven distributions of wealth. In sum, West uses a wealth of ethnographic detail to illustrate the intersection of ecological, economic, social, and semiotic factors, suggesting how a marketing focus on private, romanticized action obscures these complexities. Notes, $22 \mathrm{pp}$. References, 24 pp. Index, 13 pp.

\section{Writing Food History: A Global Perspective. Kyri W. Claflin and Peter Scholliers, eds. London: Berg, 2012. 296 pp.}

In Writing Food History, editors Kyri W. Claflin and Peter Scholliers bring together twelve essays that survey the state of historically informed food studies around the world. Written in English and dominated by chapters about the global West, the book nevertheless takes stock of scholarship about food in the Middle East, South and East Asia, and Africa, and it includes an extensive bibliography that cites works in twelve languages and references more than one thousand volumes. In addition, the introduction notes a range of additional general resources, including online bibliographies. Chapters about Europe rely on written records and include essays devoted to food scholarship in and about the ancient world, the Middle Ages, the early modern period, and modern Europe. Some chapters - such as those about India, the United States, and Africa - use (very broad) geo-political boundaries as an organizing factor, while others focus more on shared cultural influences, as in treatments of the Iberian World, the Ottoman Empire, Arab cuisine, Jewish food writing, and the interconnected foodways of Japan, China, and Korea. Some chapters offer more information about foodways, seeking, for instance, to clarify misconceptions about food choice and aesthetics in Medieval Europe or to remind readers that on the African continent, food is a diverse tool for expression, not merely survival. Others are more concerned with the intersection of scholarly and social movements, as in Amy Bentley's discussion of how countercultural interests challenged consensus histories that presented the United States as a nation of egalitarian abundance, or Krishnendu Ray's call for more exchange between entrenched, divergent approaches to Indian food studies. Some authors weigh in on what "counts" as history and who counts as a historian; all emphasize the increasing interdisciplinarity of food studies and note the value of ethnographic research, idiosyncratic source texts, and increasing attention to the aesthetic and cultural dimensions of food. Not surprisingly, the French Annales school and Sidney Mintz's pioneering work on the transatlantic politics of sugar are mentioned repeatedly throughout the volume. Authors also note increasing attention to food in semi-public spaces, to the roles food plays in heritage politics, and to the ways texts about food relate to actual food practices. The editors' introductory chapter explains why historiography matters, that is, why reflection on the patterns and shifts extant in secondary sources, not just primary ones, is important for sound, vibrant, and ethical scholarship; their concluding chapter is itself a historiographical essay on Writing Food History, noting patterns in the questions, methods, sources, trajectories, and scholarly influences found throughout the book. The collection is a valuable tool for food researchers of every stripe. Bibliography, $66 \mathrm{pp}$. Index, $12 \mathrm{pp}$. 
Wine and Culture: Vineyard to Glass. Rachel E. Black and Robert C. Ulin, eds. London: Bloomsbury, 2013. 323 pp.

As its name suggests, Wine and Culture: Vineyard to Glass is an anthropological exploration of wine in all its material and social senses: the book's contributors not only address the physical characteristics of cultivars and vineyards and the processes involved in cultivation and vinification, but they also examine the narratives, laws, practices, and other sociocultural contexts that link wine-the-commodity to quality and status - to culture with a capital C. The book's fifteen contributors offer case studies that span Western and Eastern Europe, as well as Australia, Chile, and Lebanon. In their introduction to the volume, editors Rachel Black and Robert Ulin note that until recent years, wine has been curiously absent from anthropological research, an omission they attribute to the discipline's historical emphasis on the bounded, the exotic, and the primitive. If wine has been too familiar to study, they argue, it's also been dismissed as merely pleasurable or dangerous. In this collection, however, authors use the production, regulation, marketing, and consumption of wine to think about issues that include place-based performances of identity and influence in the contexts of globalization and shifting political regimes; multiplex representations of tradition and innovation; the implications of commodity fetishism; and the ways that invoking terroir can both disguise and reveal a wine's conditions of production. Each of the book's four sections-"Rethinking Terroir," "Relationships of Power and the Construction of Place," "Labor, Commodification, and the Politics of Wine," and "Technology and Nature"-includes a short introduction that contextualizes these big ideas within broader cultural scholarship. Bibliography, $20 \mathrm{pp}$. Index, 5 pp.

\section{Rice and Beans: A Unique Dish in a Hundred Places. Richard Wilk and Livia Barbosa, eds. London: Berg, 2012. 282 pp.}

Like many studies of food, Rice and Beans: A Unique Dish in a Hundred Places illuminates the paths and consequences of human mobility, creativity, and ability to invest material objects with symbolic meaning. But this edited volume seeks to avoid the two primary modes that structure many such studies: by focusing on a typical dish, rather than a geographic locale or an isolated ingredient, the authors hope to drill down to those variations in preparation, consumption, and narration that have been made semiotically significant. As editors Richard Wilk and Livia Barbosa explain in their introductory chapter, this kind of targeted comparative work helps to clarify cultural grammars - those rules by which meaning is organized and expressed - focusing attention on human agency in the context of specific sites and histories. For instance, the distribution of similar rice-and-bean foodways - from Africa, through Cuba, Jamaica, the Eastern Caribbean, Brazil, Guyana, Panama, Costa Rica, Belize, Mexico, and New Orleansmaps closely onto the general culture area that has been called the Black Atlantic. But as the collection's main chapters reveal, the specific legumes preferred, the flavor principles employed, the manner of procuring and combining the key ingredients, and the local stories and debates linked to beans and rice in each locale all reveal unique experiences of colonization, human trafficking, political sovereignty, international trade, climate and topography, class, ethnicity, and many other factors. Sidney Mintz closes the volume by reflecting on his own experience with arroz y habichuelas, hunger, and poverty in mid-century Puerto Rico, offering a word of 
caution about the nutritional consequences of global shifts toward polished white rice and away from alternative whole grains. In addition to the two framing essays and twelve case studies, Rice and Beans includes 27 black and white illustrations, a number of recipes, and an eight-page index.

Food and the Self: Consumption, Production and Material Culture. Isabelle de Solier. London: Bloomsbury, 2013. 199 pp.

In Food and the Self: Consumption, Production and Material Culture, Isabelle de Solier uses ethnographic methods to investigate contemporary fascination with eating, making, and talking about food. Building on scholarship about "productive leisure" in a postindustrial context, de Solier interprets feedback collected between 2007 and 2009 from fifty self-identified "foodies" in Melbourne, Australia, most of whom were highly educated residents of gentrified inner-city neighborhoods. Her fieldwork involves interviews and questionnaires, as well as trips to kitchens, markets, and restaurants. Significantly, de Solier pairs attention to the production and consumption of food with attention to the production and consumption of food media; that is, she considers reflexivity in the form of vernacular food blogs, restaurant reviews, and instructional videos in addition to discussing how her consultants interact with professional food writing and "material lifestyle television" (118). She concludes that as these foodies shop, dine, prepare, serve, learn, and share about food, they are crafting selves grounded in moral-though not necessarily ethical/other-oriented - notions regarding appropriate content, quantity, and mode of consumption. Furthermore, this "new secular material morality" (169) privileges informed production (DIY craft) over even informed consumption, articulating an anti-consumerist/antielitist stance that disdains accumulation and gourmet snobbery, while at the same time supporting the purchase or creation of "quality" foods that boast varied, distinctive, and known origins. The book brings together research in cultural studies, material culture, new media, sociology, and anthropology, and it will be useful for readers interested in elective identities and the longstanding rhetorical linkages between virtue and handcraft. In addition, de Solier's work offers perspectives on modes of cultural transmission; on dichotomies that include amateur/expert, work/leisure, and local/global; and on specific phenomena such as molecular gastronomy and the Slow Food movement. Bibliography, 18 pp. Index, 9 pp.

Dr. Danille Elise Christensen is Senior Lecturer in the Department of English at The Ohio State University, where she is also affiliated with the Center for Folklore Studies. Her work examines how complex cultural performances-including college football, slack key guitar, and embellished scrapbooks - are framed both materially and verbally, revealing the regimes of value (and values) in which they are embedded. She has published in the Journal of American Folklore and the Journal of Folklore Research. With funding from the American Folklife Center and the Charles Redd Center for Western Studies, she is completing a book about the changing meanings of home canning in the United States during the 20th century.

http://dx.doi.org/10.14434/mar.v8i1.12827 